\title{
Adult Health Status Among Native American Families Participating in the Growing Resilience Home Garden Study
}

\author{
Christine M. Porter, $\mathrm{PhD}^{1}$; Alyssa M. Wechsler, MA ${ }^{1}$; Shawn J. Hime, MS ${ }^{2}$; Felix Naschold, PhD ${ }^{3}$
}

\begin{abstract}
Accessible Version: www.cdc.gov/pcd/issues/2019/19_0021.htm
Suggested citation for this article: Porter CM, Wechsler AM, Hime SJ, Naschold F. Adult Health Status Among Native American Families Participating in the Growing Resilience Home Garden Study. Prev Chronic Dis 2019;16:190021. DOI: https:// doi.org/10.5888/pcd16.190021.
\end{abstract}

\section{PEER REVIEWED}

\section{Summary}

What is already known on this topic?

As survivors of historical trauma, the Northern Arapaho and Eastern Shoshone tribes sharing the Wind River Indian Reservation (WRIR) in Wyoming have significant health disparities, but very little data on this population have been published.

\section{What is added by this report?}

This research is the first to share data on adult health status in the WRIR. We found that this group of adults had worse average health status than adults at state and national levels, including American Indians/Alaska Natives as a whole.

What are the implications for public health practice?

This nation's traumatic colonization history suggests that health promotion interventions alone cannot reduce health disparities this population. Still, access to effective interventions should be available to every Native family.

\section{Abstract}

Northern Arapaho and Eastern Shoshone tribes sharing the Wind River Indian Reservation (WRIR) in Wyoming reportedly die 30 years earlier than whites in the state. We analyzed data on the health status of 176 adults from 96 families who participated in a randomized controlled trial to assess health effects of home gardens. Measures of body mass index, waist circumference, blood pressure, hemoglobin A1c, vitamin D, low-density lipoprotein cholesterol, and household food security were collected from participating adults before the intervention. Results indicated that this group has considerably worse health status than average US adults and also fares worse than average American Indians/Alaska Natives. To help improve these disparities, Native Americans need access to appropriate and effective means of health promotion.

\section{Objective}

As survivors of historical trauma, the Northern Arapaho and Eastern Shoshone tribes sharing the WRIR in Wyoming reportedly die 30 years earlier than whites in the state (1). However, only 2 peerreviewed studies with WRIR health data have been published, both of which focused on children $(2,3)$. This research is the first to share data on adult health status in the WRIR. We analyzed biometric, whole-blood, and survey-based data that were collected on 176 adults from 96 families who enrolled in Growing Resilience, a randomized controlled trial to assess the effects of home food gardens on health.

\section{Methods}

Families were eligible to enroll in Growing Resilience if they 1) lived in the WRIR, 2) had at least 1 participating family member identifying as enrolled in a federally recognized tribe, 3 ) had at least 2 adults (or 1 for single-adult families) willing to participate in 2 years of gardening and health data collection, and 4) were interested in receiving and maintaining a home food garden but had not had a food garden over 30 square feet the previous year. Project partners aimed to recruit 100 families over 3 years, 2016-2018, and administered screening forms for eligibility. Recruitment and promotion activities included newspaper advertisements, flyers, open houses, and word of mouth. Overall, 119 interested families were eligible and were invited to enroll in the study. Of those, 96 families ( $81 \%$ ) enrolled in the study immediately before their first health data collection. We report results for the 176 adults (aged $\geq 20 \mathrm{y}$ ) in those families.

We collected biometric, blood draw, and survey (up to 46 questions) data. Researchers measured height and weight for body 
mass index calculations using a Seca 213 Mobile Stadiometer (Seca) and a Tanita SC-331S Body Composition Analyzer (Tanita); assessed blood pressure using an Omron 10 Plus Series upper arm blood pressure monitor with ComFit Cuff (Omron Healthcare); and measured waist circumference using a Gulick II tape measure (Gulick). Whole blood analysis included hemoglobin A1c (HbA1c), vitamin D, and low-density lipoprotein (LDL) cholesterol (conducted by LabCorp). We tested for sex differences in all health indicators using a 2-sample Kolmogorov-Smirnov test for equality of distributions. The survey included demographic questions, and heads of households were administered the US Department of Agriculture household food security 6-question module (adapted to report on previous month) (4). Study protocol details are available elsewhere (5). The Growing Resilience study was approved by the University of Wyoming institutional review board.

\section{Results}

Of the 176 adults, $63 \%$ were female and $37 \%$ were male. Participant ages were evenly distributed (19\%-25\% per category) with the exception of adults aged 60 to 69 years $(12 \%)$ and those aged 70 or older $(<3 \%)$. Of the 170 adults who identified their tribal affiliation, $44 \%$ identified as Northern Arapaho, $40 \%$ as Eastern Shoshone, $3 \%$ as both, and $13 \%$ as another tribe. Most adults (91\%) were overweight or obese, and more than one-third (37\%) were categorized as obese class II or III (Table). Just over threequarters had high blood pressure, more than half of whom had stage 2 hypertension.

Blood measures indicated that a little more than half of adults for whom LDL cholesterol results were collected $(n=163)$ had normal levels, and nearly $80 \%$ of adults had deficient vitamin D levels $(\leq 20 \mathrm{ng} / \mathrm{mL} ; \mathrm{n}=167)$. Almost half of adults had normal $\mathrm{HbA} 1 \mathrm{c}$ levels, one-third had levels that indicated prediabetes, and $19 \%$ had diabetes $(n=167)$. Of those with diabetes, 4 were undiagnosed (ie, did not self-report as diabetic, but had HbAlc $\geq 6.5 \%$; these participants were notified). Nearly all women (95\%) and most men $(80 \%)$ had waist circumference measures associated with higher risk of obesity-related disease.

The only measure in which a difference by sex was found was blood pressure; men had higher systolic $(\mathrm{D}=0.368, P<.001)$ and diastolic $(\mathrm{D}=0.278, P=.002)$ blood pressure than women. At the family level, $65 \%$ of the 94 responding heads of household reported being food insecure during the previous month. Of those, 20 households (21\%) had very low food security, and 15 households $(16 \%)$ had marginal food security.

\section{Discussion}

These members of the Northern Arapaho and Eastern Shoshone living on the WRIR in Wyoming suffer worse average health status than adults at state and national levels, including among American Indians/Alaska Natives (AIs/ANs) at large (Figure). Their obesity rate is $70 \%$ higher than the national AI/AN average (6), hypertension rates are more than double (7), and high LDL cholesterol rates are one-third higher (8). The diabetes rate is 2.3 times the Wyoming average and $23 \%$ higher than $\mathrm{AI} / \mathrm{AN}$ averages (6). Their $65 \%$ food insecurity rate is more than 10 times the national 30 -day rate (9).

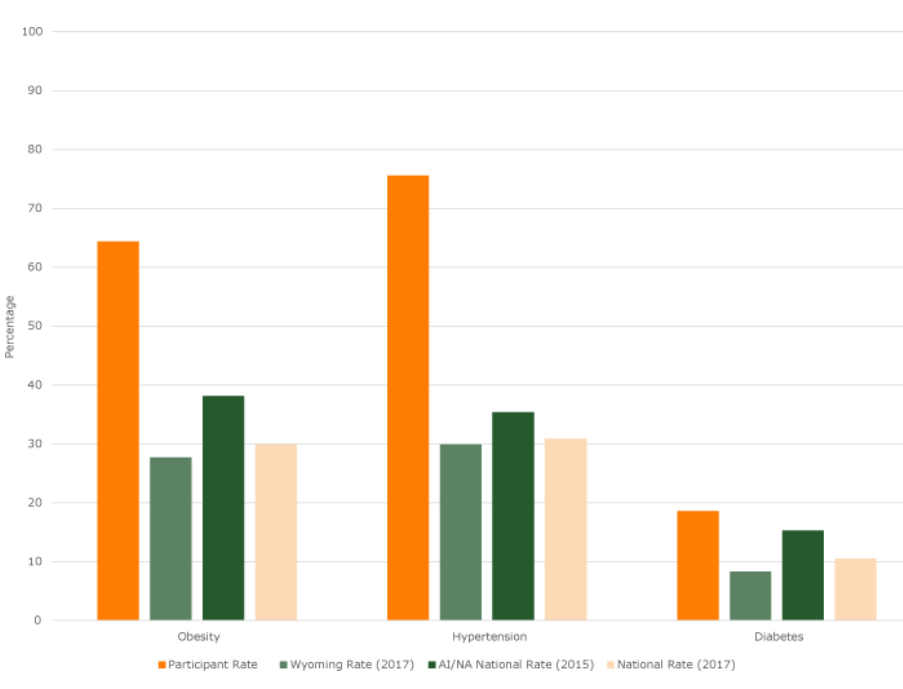

Figure. Rates of obesity, hypertension, and diabetes among adult Growing Resilience participants before any intervention compared with state and national rates. State and national data are from the Behavioral Risk Factor Surveillance System (6,7). Abbreviation: Al/AN, American Indian/Alaska Native.

Our study has limitations. The small sample size constrains analyses by sex or age, and data were not taken from a random sample. WRIR-wide estimates reported by tribal health affiliates (10) and findings in this sample did roughly align for obesity $(71 \%$ reported vs $64.4 \%$ here) and diagnosed diabetes (12\% reported vs $16.2 \%$ here). Although our results may not be fully generalizable to the WRIR adult population, the severity of poor health in this sample suggests that WRIR communities are living with enormous health challenges, many of which can result in death if left untreated (11). These data also currently comprise the most complete set that is publicly available about adult health status in WRIR.

To begin addressing these challenges and reducing these health disparities, Native American families need access to multiple and

\footnotetext{
The opinions expressed by authors contributing to this journal do not necessarily reflect the opinions of the U.S. Department of Health and Human Services, the Public Health Service, the Centers for Disease Control and Prevention, or the authors' affiliated institutions.
} 
effective means to control and enhance health $(12,13)$. The Growing Resilience study is assessing to what extent home gardening provides one such means. Although this nation's traumatic colonization history suggests health promotion interventions alone cannot remedy such large health disparities, access to effective interventions should be available to every Native family.

\section{Acknowledgments}

The Growing Resilience study is registered at www.clinicaltrials.gov (no. NCT02672748) and was funded by the National Heart, Lung, and Blood Institute and the National Institute of General Medical Sciences (NIGMS), National Institutes of Health (NIH) (grant no. R01 HL126666-01). It was approved by the University of Wyoming, Northern Arapaho Business Council, and Eastern Shoshone Business Council. The 2013 pilot work was funded by NIGMS/NIH grant no. 8 P20 GM103432-12.

\section{Author Information}

Corresponding Author: Alyssa M. Wechsler, MA, Division of Kinesiology and Health, University of Wyoming, 1000 E. University Ave, Department 3196, Laramie, WY 82071. Telephone: 307-399-3247. Email: alywex@uwyo.edu.

Author Affiliations: ${ }^{1}$ Division of Kinesiology and Health, University of Wyoming, Laramie, Wyoming. ${ }^{2}$ Wyoming Survey \& Analysis Center, University of Wyoming, Laramie, Wyoming. ${ }^{3}$ Department of Economics, University of Wyoming, Laramie, Wyoming.

\section{References}

1. Williams T. Brutal crimes grip an Indian reservation. New York Times. February 3, 2012.

2. Smith DT, Bartee RT, Dorozynski CM, Carr LJ. Prevalence of overweight and influence of out-of-school seasonal periods on body mass index among American Indian schoolchildren. Prev Chronic Dis 2009;6(1):A20.

3. Perkins GB, Church GM. Report of pediatric evaluation of a sample of Indian children-Wind River Indian Reservation, 1957. Am J Public Health Nations Health 1960;50(2):181-94.

4. Bickel G, Nord M, Price C, Hamilton W, Cook J. Guide to measuring household food security. Alexandria (VA): US Department of Agriculture, Food and Nutrition Service; 2000.

5. Porter CM, Wechsler AM, Naschold F, Hime SJ, Fox L. Assessing health impacts of home food gardens with Wind River Indian Reservation families: protocol for a randomised controlled trial. BMJ Open 2019;9(4):e022731.
6. Centers for Disease Control and Prevention. Behavioral Risk Factor Surveillance System survey data. Atlanta (GA): US Department of Health and Human Services, Centers for Disease Control and Prevention; 2015.

7. Centers for Disease Control and Prevention. Behavioral Risk Factor Surveillance System survey data. Atlanta (GA): US Department of Health and Human Services, Centers for Disease Control and Prevention; 2017.

8. Mercado C, DeSimone AK, Odom E, Gillespie C, Ayala C, Loustalot F. Prevalence of cholesterol treatment eligibility and medication use among adults — United States, 2005-2012. MMWR Morb Mortal Wkly Rep 2015;64(47):1305-11.

9. Coleman-Jensen A, Gregory CA, Rabbitt MP. Frequency of food insecurity. US Department of Agriculture Economic Research Service; 2018. https://www.ers.usda.gov/topics/foodnutrition-assistance/food-security-in-the-us/frequency-of-foodinsecurity/\#temporal. Accessed October 31, 2018.

10. Alliance to Reduce Disparities in Diabetes. Reducing diabetes disparities in American Indian communities (Wind River Reservation). 2011. http://ardd.sph.umich.edu/eastern_ shoshone tribe.html. Accessed November 21, 2014.

11. Copeland M. Generation of hope: future of Native health depends on kids. WyoFile; 2015. https://www.wyofile.com/ generation-hope-future-native-health-depends-kids/. Accessed April 4, 2019.

12. Satterfield D, DeBruyn L, Santos M, Alonso L, Frank M. Health promotion and diabetes prevention in American Indian and Alaska Native communities - Traditional Foods Project, 2008-2014. MMWR Suppl 2016;65(1):4-10.

13. Sequist TD, Cullen T, Acton KJ. Indian health service innovations have helped reduce health disparities affecting American Indian and Alaska Native people. Health Aff (Millwood) 2011;30(10):1965-73.

The opinions expressed by authors contributing to this journal do not necessarily reflect the opinions of the U.S. Department of Health and Human Services, the Public Health Service, the Centers for Disease Control and Prevention, or the authors' affiliated institutions. 


\section{Table}

Table. Outcomes From Biometric, Whole Blood, and Survey Measures, Participants of the Growing Resilience Project, Wind River Indian Reservation, Wyoming, 2016-2018

\begin{tabular}{|c|c|c|c|}
\hline \multirow[b]{2}{*}{ Measure } & Female & Male & Overall \\
\hline & \multicolumn{3}{|c|}{$\%$} \\
\hline \multicolumn{4}{|l|}{ Body mass index $\left(\mathrm{kg} / \mathrm{m}^{2}\right), \mathrm{n}=174$ adults (110 female, 64 male) } \\
\hline Underweight (<18.5) & 1.8 & 0 & 1.1 \\
\hline Normal weight $(18.5$ to $<25)$ & 6.4 & 9.4 & 7.5 \\
\hline Overweight $(25$ to $<30)$ & 24.6 & 31.3 & 27.0 \\
\hline Obese class I (30 to <35) & 26.4 & 29.7 & 27.6 \\
\hline Obese class II $(35$ to $<40)$ & 23.6 & 15.6 & 20.7 \\
\hline Obese class III ( $\geq 40)$ & 17.3 & 14.1 & 16.1 \\
\hline \multicolumn{4}{|l|}{$\mathrm{BP}, \mathrm{n}=176$ adults (111 female, 65 male) ${ }^{a}$} \\
\hline Normal BP (systolic BP <120 mm Hg AND diastolic BP < 80 mm Hg) & 19.8 & 12.3 & 17.0 \\
\hline Prehypertension (systolic BP 120-129 mm Hg AND diastolic BP <80 mm Hg) & 9.0 & 4.6 & 7.4 \\
\hline Stage 1 hypertension (systolic BP 130-139 mm Hg OR diastolic BP 80-89 mm Hg) & 36.9 & 21.6 & 31.3 \\
\hline Stage 2 hypertension (systolic BP $\geq 140$ mm Hg OR diastolic BP $\geq 90 \mathrm{~mm} \mathrm{Hg}$ ) & 34.2 & 61.6 & 44.3 \\
\hline \multicolumn{4}{|l|}{ Diabetes status, $\mathrm{n}=167$ adults (105 female, 62 male) } \\
\hline Normal hemoglobin A1c (<5.7\%) & 51.4 & 43.6 & 48.5 \\
\hline Prediabetes (hemoglobin A1c 5.7\%-6.4\%) & 31.4 & 35.5 & 32.9 \\
\hline Controlled diabetes (self-identifies as having diabetes AND has hemoglobin A1c <7\%) & 5.7 & 9.7 & 7.2 \\
\hline Not controlled diabetes (self-identifies as having diabetes AND has hemoglobin A1c $\geq 7 \%$ ) & 8.6 & 9.7 & 9.0 \\
\hline Undiagnosed diabetes (does not self-identify as having diabetes AND has hemoglobin A1c $\geq 6.5 \%$ ) & 2.9 & 1.6 & 2.4 \\
\hline \multicolumn{4}{|l|}{ Vitamin $D, n=167$ adults (105 female, 62 male) } \\
\hline Adequate vitamin $\mathrm{D}(\geq 30 \mathrm{ng} / \mathrm{mL})$ & 8.6 & 1.6 & 6.0 \\
\hline Possibly insufficient vitamin $\mathrm{D}(>20$ to $<30 \mathrm{ng} / \mathrm{mL})$ & 13.3 & 17.7 & 15.0 \\
\hline Vitamin $\mathrm{D}$ deficient $(\leq 20 \mathrm{ng} / \mathrm{mL})$ & 78.1 & 80.7 & 79.0 \\
\hline \multicolumn{4}{|l|}{ LDL Cholesterol, $\mathrm{n}=163$ (104 female, 59 male) } \\
\hline Normal LDL cholesterol (<100 mg/dL) & 47.1 & 57.6 & 50.9 \\
\hline High LDL cholesterol ( $\geq 100 \mathrm{mg} / \mathrm{dL})$ & 52.9 & 42.4 & 49.1 \\
\hline \multicolumn{4}{|l|}{ Waist circumference, $n=176$ adults ( 111 female, 65 male) } \\
\hline Healthy waist circumference among women ( $<35 \mathrm{in})$ and men ( $<40$ in) & 5.4 & 20.0 & NA \\
\hline \multicolumn{4}{|l|}{ Household food security previous month, $n=94$ households } \\
\hline High food security (raw score of 0 affirmatives) & NA & NA & 19.1 \\
\hline Marginal food security ( 1 affirmative) & NA & NA & 16.0 \\
\hline Low food security (2-4 affirmatives) & NA & NA & 43.6 \\
\hline Very low food security (5 affirmatives; 6 th question was not asked) & NA & NA & 21.3 \\
\hline
\end{tabular}

Abbreviations: BP, blood pressure; LDL, low-density lipoprotein; NA, not applicable.

${ }^{a}$ Using 2-sample Kolmogorov-Smirnov tests for equality of distributions to test for sex differences in the individual health measures in this tables showed only BP as significantly different, with men having higher systolic $(D=0.368, P<.001)$ and diastolic $(D=0.278, P=.002) B P$.

The opinions expressed by authors contributing to this journal do not necessarily reflect the opinions of the U.S. Department of Health and Human Services, the Public Health Service, the Centers for Disease Control and Prevention, or the authors' affiliated institutions. 